\title{
EDITORIAL
}

\section{A NEW SPECIALITY}

The introduction of Army Community and Occupational Medicine (ACOM) means that all RAMC medical officers are now firmly committed to postgraduate professional training. The days are past when a first degree alone was enough to support a career in medicine, military or civilian. Henceforth for the RAMC there will be three professional and specialist streams - General Practice (today just as much a speciality in fact if not yet in name), the clinical or hospital specialities and ACOM.

The speciality ranges across a professional spectrum from those whose work is predominantly concerned with the organization, planning and management of medical care in peace and war for soldiers and their dependants - the community medicine stream - to medical officers whose highly specialized task is to provide an occupational medical service for Army aviators - the occupational medicine stream. In the centre, perpetuating the Army Health tradition, stand those who for want of a better name may collectively be entitled the preventive medicine stream. This group will embody the academic back-up as well as the more esoteric expertise in prevention, research and control of communicable disease that the specialty must embrace if it is to flourish as a scientific medical discipline.

The professional basis to the conjoined especialty will be built upon epidemiology and prevention. For most, but particularly for the community medicine stream who form the larger part of the specialty, the training will lead to the Membership of the Faculty of Community Medicine (MFCM). At the other end specialists in Army Aviation Medicine, from the same common theme as the rest, will proceed to higher qualifications in occupational medicine although the guide lines for this are not yet clear. And in the centre, for the academic preventive stream the expectation will be for dual qualification.

Some may question the wisdom of combining community and occupational medicine into one specialty but there is no doubt that Army Health, previously Army Hygiene, has for many years, and certainly for far longer than the existence of the two civilian specialties, been concerned with the comprehensive care of the soldier at work - in both peace and war - and at play, thus providing (however you interpret the titles) a truly comprehensive occupational and community medical service. The Army is a community, albeit small by NHS standards, but one whose medical problems spring from its complex role, its versatility and mobility. Equally the Army provides an occupation across a vast and increasing technological range where the health hazards are legion. Ensuring in these circumstances that health has no ill effect on work, nor work on health, fulfils the fundamental aims of an occupational medical service. Thus it seems that the conjoined specialty is founded on logioal precepts. This Journal wishes it every success for the future. 